Check for updates

Cite this: RSC Adv., 2021, 11, 12330

Received 13th January 2021

Accepted 24th March 2021

DOI: $10.1039 / \mathrm{d} 1 \mathrm{ra00288 \textrm {k }}$

rsc.li/rsc-advances

\section{Inorganic process for wet silica-doping of calcium phosphate $\dagger$}

\begin{abstract}
Yuki Sugiura, (D) *a Kodai Niitsu, ${ }^{\text {b }}$ Yasuko Saito, ${ }^{c}$ Takashi Endo ${ }^{c}$ and Masanori Horie (D) ${ }^{a}$
Silica is not only a biocompatible trace element but also an essential element for bone formation and metabolism. Therefore, it is often doped into bioceramics such as calcium phosphate and calcium carbonate for enhancing biomaterial ability. Heretofore, organic silica materials are employed as silica sources, but the residual organic matter is a significant drawback in biomaterial applications. Therefore, in this study, we introduce a one-pot inorganic synthesis method for the formation of silica-doped octacalcium phosphate (OCP) using $\mathrm{Na}_{2} \mathrm{SiO}_{3}$ as the silica source. Silica was intercalated into the OCP unit lattice, replacing its hydrous layer structure, and then a layer-by-layer structure of apatite and silica was formed. Furthermore, by immersing the fabricated silica-doped OCP into suitable solutions, both silica-doped hydroxyapatite and carbonate apatite were fabricated through a one-step inorganic processes.
\end{abstract}

\section{Introduction}

Since the 1960s, silica $\left(\mathrm{SiO}_{4}{ }^{4-}\right)$ has been known to stimulate and enhance bone cell activities and upregulate the bone remodelling process. ${ }^{1-3}$ Especially, silica enhances the activity and purification of osteoblasts as reinforcing alkali phosphatase and type-I collagen generation and inhibits the activity of osteoclasts. ${ }^{4-6}$ Moreover, silica-doped biomaterials, due to their excellent biocompatibility, are considered attractive for bone substitutes.

Various works have investigated silica-doped biocompatible ceramics, such as calcium carbonate and calcium phosphate. ${ }^{7-10}$ For example, silica-doped vaterite, a metastable phase of calcium carbonate, has been found to significantly upregulate osteoblast activities such as alkali phosphatase generation and viability. ${ }^{7,11}$ However, silica-doping processes of calcium carbonate and calcium phosphates based on wet-chemical systems have significant drawbacks. Although organic silica materials such as tetraethyl orthosilicate (TEOS) and hexamethyldisilane have been employed as silica sources for doping via in situ hydrolysis, the residual organic matter from silica sources might exhibit toxicity. ${ }^{7,8,11,12}$

Octacalcium phosphate [OCP: $\mathrm{Ca}_{8} \mathrm{H}_{2}\left(\mathrm{PO}_{4}\right)_{6} \cdot 5 \mathrm{H}_{2} \mathrm{O}$ ] exhibits excellent biocompatibility and can function as a bone

${ }^{a}$ Health and Medical Research Institute, National Institute of Advanced Industrial Science and Technology (AIST), Kagawa, 761-0395, Japan. E-mail: yuki-sugiura@ aist.go.jp

${ }^{b}$ Department of Material Science and Engineering, Kyoto University, Kyoto 606-8501, Japan

${ }^{c}$ Research Institute for Sustainable Chemistry, National Institute of Advanced Industrial Science and Technology (AIST), Hiroshima, 739-0046, Japan

$\dagger$ Electronic supplementary information (ESI) available. See DOI: 10.1039/d1ra00288k replacement material through bone remodeling. ${ }^{13-16}$ In addition, OCP functions as a precursor material for various calcium phosphates, such as apatite, through solid-solid phase conversion processes. ${ }^{17-19}$ Therefore, silica-doped OCP can lead to the introduction of various silica-doped calcium phosphates.

A technique for fabricating silica-doped OCP in sodium silicate $\left(\mathrm{Na}_{2} \mathrm{SiO}_{3}\right)$ solutions would be valuable for the silicadoping of calcium phosphate; therefore, in this study, we investigated silica-doped OCP formed through hydrolysis process in inorganic $\mathrm{Na}_{2} \mathrm{SiO}_{3}$ solutions.

\section{Material and methods}

\section{Materials}

All reagents were purchased from FUJI Film Wako Pure Chem Inc., Japan. The compounds $\mathrm{Na}_{2} \mathrm{SiO}_{3}$ and $\left(\mathrm{NH}_{4}\right)_{2} \mathrm{CO}_{3}$ were dissolved in distilled water to form solutions. The mother experimental solutions were prepared as $5.0 \mathrm{~mol} \mathrm{~L}^{-1} \mathrm{Na}_{2} \mathrm{SiO}_{3}$ and $2.0 \mathrm{~mol} \mathrm{~L}^{-1}\left(\mathrm{NH}_{4}\right)_{2} \mathrm{CO}_{3}$; then, they were diluted with distilled water for solution preparation.

A $2.39 \mathrm{~g}$ sample of dicalcium hydrogen phosphate dihydrate (DCPD: $\mathrm{CaHPO}_{4} \cdot 2 \mathrm{H}_{2} \mathrm{O}, 14 \mathrm{mmol}$ ) was immersed in $20 \mathrm{~mL}$ of the abovementioned solutions at $60{ }^{\circ} \mathrm{C}$ for 1 day. The initial and final $\mathrm{pH}$ values of the solutions were recorded at room temperature using a $\mathrm{pH}$ electrode (LAQUA ToupH 9615S-10D with $\mathrm{pH}$ meter D-72, Horiba Co., Kyoto, Japan). The treated samples were washed with distilled water several times to remove the residual solutions and then placed in a drying oven at $60{ }^{\circ} \mathrm{C}$ for several hours.

\section{Characterization}

The crystallographic information about the samples was obtained via X-ray diffraction (XRD: MiniFlex600, Rigaku Co., 
Japan) at an acceleration voltage and amplitude of $40 \mathrm{kV}$ and 15 $\mathrm{mA}$, respectively. The diffraction angle was continuously scanned over $2 \theta$ values ranging from $3^{\circ}$ to $70^{\circ}$ at a scanning rate of $5^{\circ} / \mathrm{min}$ for characterization and from $2^{\circ}$ to $12^{\circ}$ at a scanning rate of $1^{\circ} \mathrm{min}^{-1}$ for crystallographic parameter analysis.

The chemical vibration scheme of the samples was characterized via Fourier-transform infrared (FTIR) spectroscopy (VERTEX, Bruker Optics Co., USA) using a triglycine sulfate detector (128 scans, resolution of $4 \mathrm{~cm}^{-1}$ ) with an attenuated total reflection prism made of diamond. The atmosphere was the background for conducting the measurements.

The ${ }^{31} \mathrm{P}$ chemical shifts of the samples were determined via solid-state nuclear magnetic resonance (NMR) spectroscopy (Varian FT-NMR, $400 \mathrm{MHz}$, Agilent Technologies Co., USA), with a resonance frequency of $161.8 \mathrm{MHz}$ for ${ }^{31} \mathrm{P}$. For the measurements, cross-polarization magic-angle-spinning (CP-MAS) ${ }^{31} \mathrm{P}$ NMR spectroscopy was performed under a CP-MAS rate of 10 $\mathrm{kHz}$. An Agilent $4 \mathrm{~mm}$ T3 CP-MAS HXY solid probe and zirconia rotors were used. The sample weight was $\sim 0.02 \mathrm{~g}$, and the contact time for the ${ }^{31} \mathrm{P}$ CP-MAS measurements was $5 \mathrm{~ms}$, with an acquisition time of $10 \mathrm{~ms}$ and relaxation delays of $40 \mathrm{~s}$ for each measurement interval. The number of repetitions per measurement was 400 . The ${ }^{31} \mathrm{P}$ chemical shift of $\left(\mathrm{NH}_{4}\right) \mathrm{H}_{2} \mathrm{PO}_{4}$ was used as an external reference $(\delta=1.0 \mathrm{ppm})$.

The fine structure of the samples was assessed via fieldemission scanning electron microscopy (FE-SEM: JSM-6700F, JEOL Co., Japan) at an acceleration voltage of $5 \mathrm{kV}$; the samples were sputter-coated using Os to prevent surface-charge accumulation. The fine atomic distribution of the samples was observed via scanning transmission electron microscopyenergy-dispersive X-ray spectroscopy (STEM-EDX, JEMARM200F, JEOL Co., Japan) at an acceleration voltage of $200 \mathrm{kV}$.

The $\mathrm{Ca}$ and $\mathrm{P}\left(\mathrm{PO}_{4}\right)$ (and $\mathrm{Na}$ ) contents of the samples were measured via inductively coupled plasma-atomic emission spectroscopy (ICP-AES: 5110VDV, Agilent Technology Co., Japan) after the samples were dissolved in $2 \% \mathrm{HNO}_{3}$ solution.

The thermal behaviour of the samples was determined via thermogravimetry-differential thermal analysis (TG-DTA; Thermo-Plus, TG8110, Rigaku Co., Japan). The weight loss ratio around $150{ }^{\circ} \mathrm{C}$ was defined as the hydrous layer consisting of $\mathrm{HPO}_{4}$ and $\mathrm{OH}$ decomposition.

The Si content of the samples was measured via X-ray fluorescence spectroscopy (XRF: SEA2210, SII Nano Technology Co., Japan) at an acceleration voltage of $15 \mathrm{kV}$ under vacuum conditions. The Si/Ca ratio was calibrated using a disk-shaped mixture of hydroxyapatite- $\mathrm{SiO}_{2}$ sintered blocks.

\section{Results and discussions}

In this study, we employed the hydrolysis of DCPD, an acidic calcium phosphate, in $\mathrm{Na}_{2} \mathrm{SiO}_{3}$ solutions, a strongly basic solution. The $\mathrm{pH}$ of the reacting solutions is an important factor for the phase conversion process, because each phase of the calcium phosphate formation was greatly dependent on the $\mathrm{pH}$. Fig. 1 shows the initial and final $\mathrm{pH}$ values of reacting solutions. With increasing $\mathrm{Na}_{2} \mathrm{SiO}_{3}$ concentration, the initial $\mathrm{pH}$ values of reacting solutions increased to reach about 13.5; likewise, the

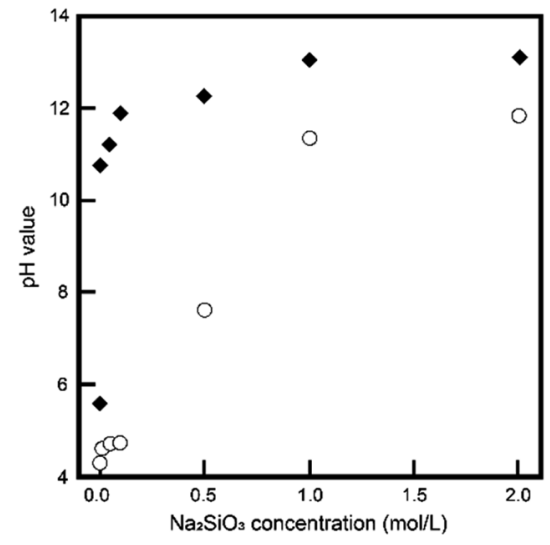

Fig. 1 The initial $(\bullet)$ and final $(O) \mathrm{pH}$ values, respectively, of the reaction solutions with different $\mathrm{Na}_{2} \mathrm{SiO}_{3}$ concentrations.

final $\mathrm{pH}$ values increased to reach about 12.0. When the $\mathrm{Na}_{2} \mathrm{SiO}_{3}$ concentration was above $1 \mathrm{~mol} \mathrm{~L}^{-1}$, the $\mathrm{pH}$ values of the reacting solutions were between 12.0 to 13.5 , as apatite preferentially formed under the solution conditions.

Then, the treated samples were characterized via XRD. Fig. 2 shows the XRD patterns of treated samples. In the cases of low $\mathrm{Na}_{2} \mathrm{SiO}_{3}$ concentration $\left(<0.2 \mathrm{~mol} \mathrm{~L}^{-1}\right)$, residual DCPD was the main phase. In the case of $0.5 \mathrm{~mol} \mathrm{~L}^{-1} \mathrm{Na}_{2} \mathrm{SiO}_{3}$, the treated samples transformed into monophasic apatite. Then, in the case of $1.0 \mathrm{~mol} \mathrm{~L}^{-1} \mathrm{Na}_{2} \mathrm{SiO}_{3}$, a strong peak at $\sim 4.7^{\circ}$, likely OCP $\mathrm{d}(100)$ peak, occurred with large parts of conventional OCP peaks. Interestingly, in the cases of $2.0 \mathrm{~mol} \mathrm{~L}^{-1} \mathrm{Na}_{2} \mathrm{SiO}_{3}$, the strong peak at $\sim 4.7^{\circ}$ was absent, and the samples appeared to transform into monophasic apatite.

In the case of $1 \mathrm{~mol} \mathrm{~L}^{-1} \mathrm{Na}_{2} \mathrm{SiO}_{3}$, the XRD pattern of the samples was similar to that of OCP. However, several ordinal peaks such as $\mathrm{d}(200)$ and $\mathrm{d}(110)$ at $\sim 9.2^{\circ}$ and $\sim 9.7^{\circ}$, respectively, were absent. In addition, the crystallinity of the obtained samples was too low to enable the effective characterization of
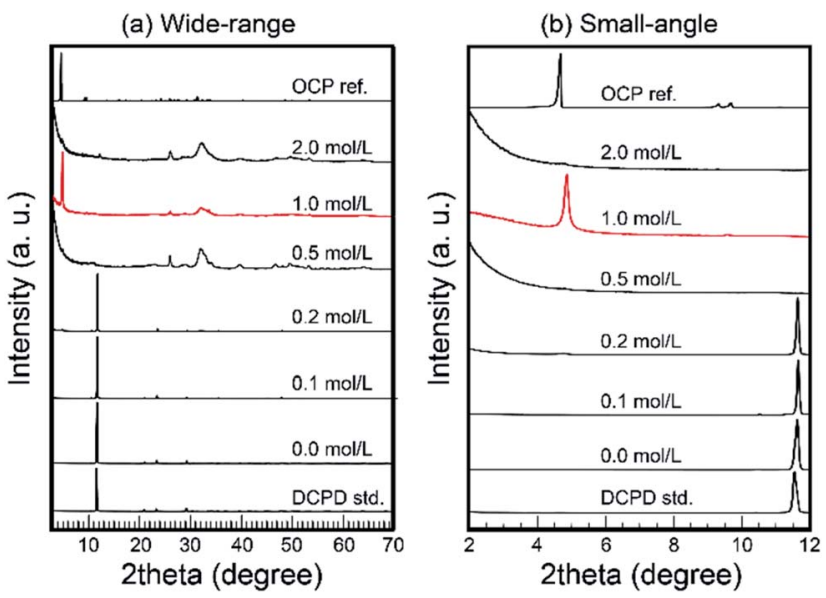

Fig. 2 Wide-range (a) and small-angle (b) XRD patterns of samples treated under various $\mathrm{Na}_{2} \mathrm{SiO}_{3}$ concentrations. Note: in the case of $1 \mathrm{~mol} \mathrm{~L}^{-1} \mathrm{Na}_{2} \mathrm{SiO}_{3}$, the XRD pattern of sample exhibited OCP pattern. 
their crystal structure. Therefore, it was considered that layered composites consisted of silica-based clay minerals.

We focused on the chemical compositions of samples. As the first step, we evaluated the silica contents of samples via XRF measurements. Fig. 3 shows the silica contents of the samples. We did not measure samples below $0.2 \mathrm{~mol} \mathrm{~L} \mathrm{~L}^{-1} \mathrm{Na}_{2} \mathrm{SiO}_{3}$ because of the large residual initial DCPD. Interestingly, the silica contents of the samples and the $\mathrm{Na}_{2} \mathrm{SiO}_{3}$ concentrations of treated solutions were inversely proportional. Through ICPAES measurements, the chemical composition of treated samples in $1 \mathrm{~mol} \mathrm{~L}^{-1} \mathrm{Na}_{2} \mathrm{SiO}_{3}$ was determined as $\mathrm{Ca}_{8} \mathrm{Na}_{1.12^{-}}$ $\mathrm{H}_{6.4}\left(\mathrm{PO}_{4}\right)_{4}\left(\mathrm{SiO}_{4}\right)_{2.88} \cdot n \mathrm{H}_{2} \mathrm{O}$ for a pure substance.

The morphologies of samples were identified via scanning electron microscopy (SEM) to confirm if the obtained materials were a pure substance or a mixture. Fig. 4 shows the SEM micrographs of treated samples. The microparticles of the treated samples exhibited plate-like crystal morphology, which is representative of DCPD crystals. Therefore, we consider that the treated samples have a pseudomorphic relationship with DCPD (Fig. 4a). In the magnified image, the surface of the treated samples consisted of closely packed $\sim 10 \mathrm{~nm}$ particles (Fig. 4b). The fine inner structure including the crystal structure of samples was determined via transmission electron microscopy (TEM). The inner structure of the samples was essentially uniform (Fig. 4c and d). Furthermore, the selected-area diffraction pattern and the STEM-high-angle annular darkfield imaging results of the treated samples indicated that the samples had enough sizes of single-crystal domains (Fig. 4e and f).

The fine chemical composition distributions of treated samples were evaluated via STEM-EDX. Fig. 5 displays the STEM-EDX mapping images of treated samples. All observed elements; $\mathrm{Ca}, \mathrm{P}$, and Si, were uniformly distributed.

Based on the bulk and microscopic evaluation, we conclude that the pure substance consisted of $\mathrm{Ca}, \mathrm{PO}_{4}$, and silica with an OCP-like crystal structure was formed when DCPD was treated in $1 \mathrm{~mol} \mathrm{~L}^{-1} \mathrm{Na}_{2} \mathrm{SiO}_{3}$ solution. Thus, we designate the treated samples as OCP-silica.

It seems that the results of XRD patterns and TEM micrographs of OCP-silica did not coincide. This phenomenon could

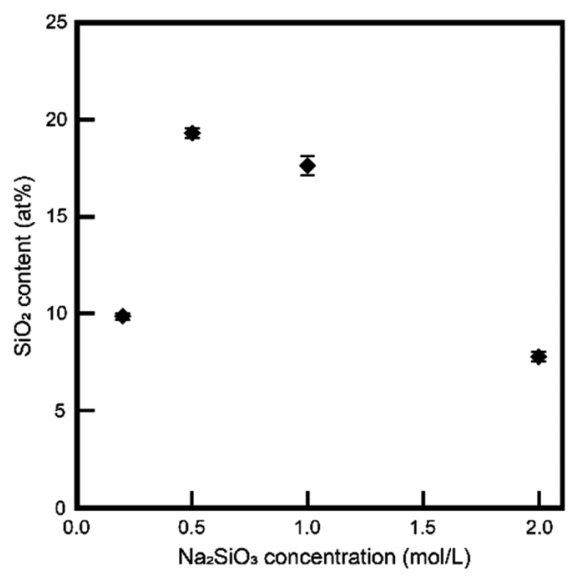

Fig. 3 Si contents of samples.
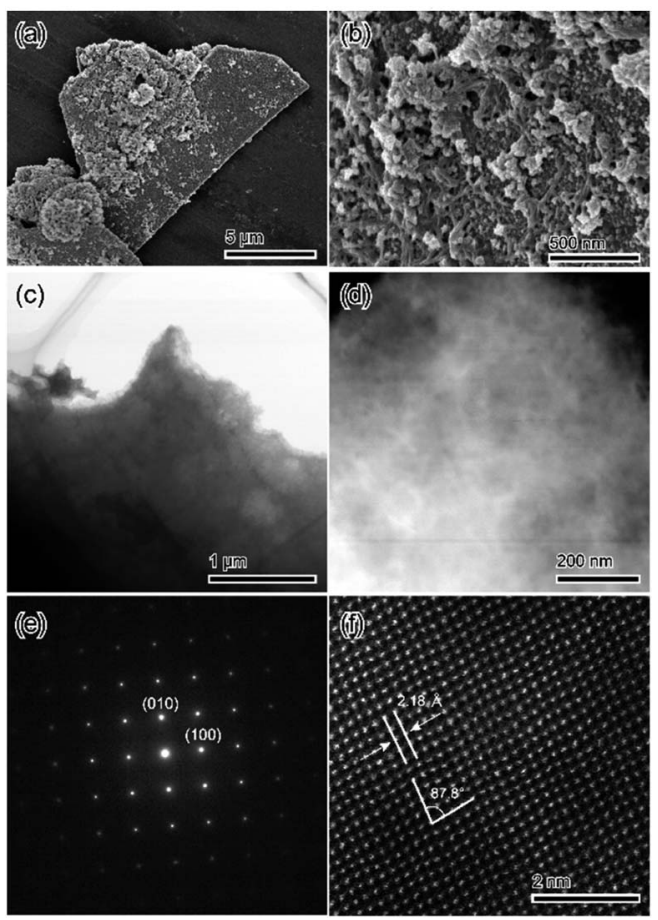

Fig. 4 Fine structure observation results of the sample treated in $1 \mathrm{~mol} \mathrm{~L}^{-1} \mathrm{Na}_{2} \mathrm{SiO}_{3}$ solutions: ( $a$ and b) whole and surface structures; (c and d) inner structure and (e and f) its crystallographic analysis.

be described the unique crystal structure of OCP composite as the laminated structure of well-arranged 2D crystal structure. When observed along the vertical direction of lamination, wellarranged fine structure could be seen in spite of the bulk layer structure. Furthermore, the results of spectroscopic and STEM observation also supported this consideration.
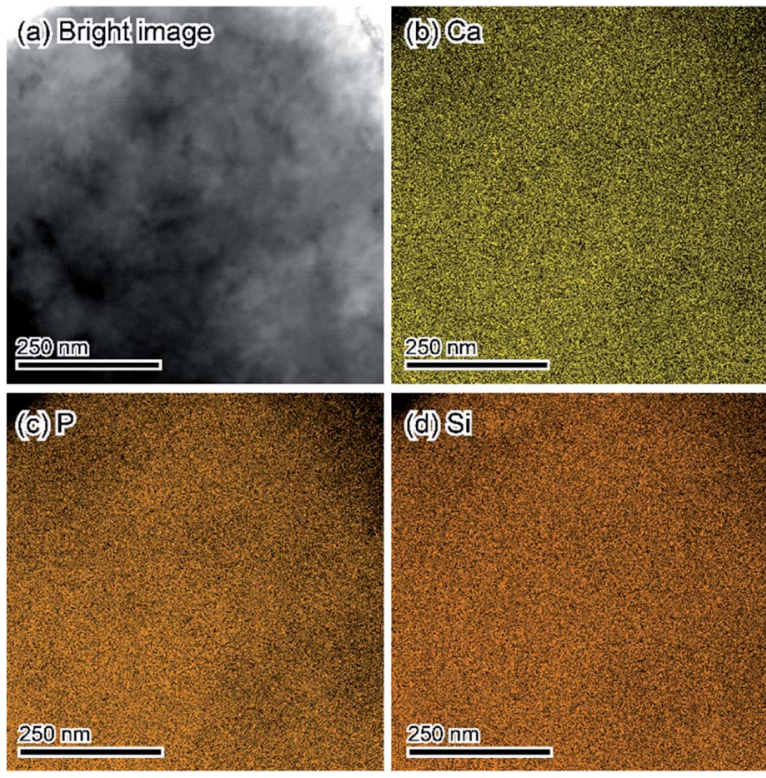

Fig. 5 STEM-EDX mapping results of the sample treated in $1 \mathrm{~mol} \mathrm{~L}^{-1}$ $\mathrm{Na}_{2} \mathrm{SiO}_{3}$ solutions corresponding to Fig. $4 \mathrm{~d}$. (a) Bright image. (b) Ca. (c) P. (d) $\mathrm{Si}$. 
Furthermore, we evaluated the physicochemical properties of OCP-silica. First, we focused on which sites were substituted by silica in the OCP crystal structure. Normally, six different states of $\mathrm{PO}_{4}(P 1$ to $P 6)$ occurred in the OCP unit lattice. Each $\mathrm{PO}_{4}$ state $\left(\mathrm{P} 1\right.$ to $\mathrm{P} \mathrm{PO}_{4}$ ) of the OCP unit lattice could be determined through spectroscopic analysis based on the OCP low symmetry crystal structure $(P \overline{1})$. Fig. 6 shows the FTIR spectra of OCP-silica with $\mathrm{SiO}_{2}$ and OCP-Na to facilitate comparison. In the case of OCP-silica, $\mathrm{PO}_{4}$ and $\mathrm{HPO}_{4}$ bands were observed, which are normally observed in OCP, with silanol bands $455 \mathrm{~cm}^{-1}$ and, around $1100 \mathrm{~cm}^{-1}$ to $1300 \mathrm{~cm}^{-1}$. Considering to
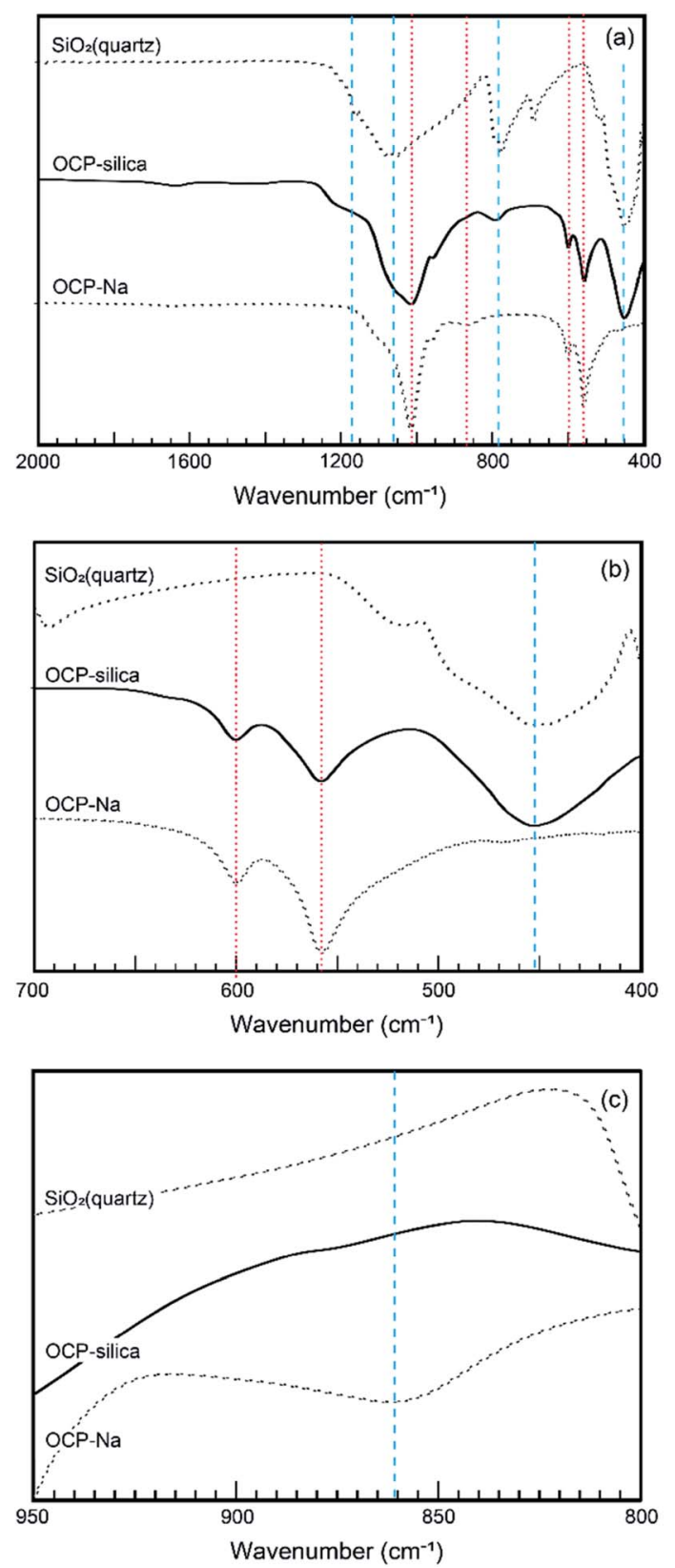

Fig. 6 FT-IR spectra of OCP-silica and reference materials (OCP-Na and $\mathrm{SiO}_{2}$ ). (a) Wide-range. (b) $P 6 \mathrm{PO}_{4}$ region. (c) $P 5 \mathrm{PO}_{4}$. Red dotted lines and blue broken lines corresponded to silica and calcium OCP, respectively. characteristic bands of quarts $\left(455 \mathrm{~cm}^{-1}\right)$, the crystallite size of silica was smaller than $3 \mu \mathrm{m} .{ }^{20}$ Moreover, we observed little $P 5$ $\mathrm{PO}_{4}$ band in OCP-silica, which is the root of the hydrous layer.

Furthermore, we evaluated the state of $\mathrm{P}_{6} \mathrm{PO}_{4}$, the centerpiece of the hydrous layer, via solid-state NMR, as it could not be well evaluated through FTIR analysis. Fig. 7 shows the ${ }^{31} \mathrm{P}$ solidstate NMR spectra of OCP-silica and OCP-Na to facilitate comparison. Based on the FTIR and solid-state NMR results, little $\mathrm{PO}_{4}$ bands corresponding to hydrous layers ( $P 5$ and $P 6$ $\mathrm{PO}_{4}$ ) were observed.

Through thermal analysis, we investigated the thermal stability of samples. Especially, for OCP, we determined the decomposition temperature and behaviour of the hydrous layer. Fig. 8 shows the DTA curves of OCP-silica and OCP-Na to facilitate comparison. In the case of OCP-silica, the decomposition of the OCP hydrous layer was hardly observed. Thus, we conclude that silica could be substituted in the OCP hydrous layer.

By tailoring $\mathrm{Ca}, \mathrm{PO}_{4}$, and silica, we could synthesize OCPsilica through a one-step process using only inorganic composites. We concluded that the silica contents of the samples did not coincide with the $\mathrm{Na}_{2} \mathrm{SiO}_{3}$ concentrations due to the two factors of solution $\mathrm{pH}$ and molar ratio of $\mathrm{Ca}$ and $\mathrm{PO}_{4}+$ silica. Several previous studies indicate that OCP was likely formed in $\mathrm{PO}_{4}$ rich solutions. ${ }^{21-23}$ This study suggests that silica also played a similar role of $\mathrm{PO}_{4}$ for OCP formation. At further concentrated conditions, high alkalinity induced apatite formation. Based on the results of XRD, FTIR, and solid-state NMR, we roughly drew a schematic illustration of OCP-silica crystal structure in Fig. 9. Briefly, silica molecules replaced the $\mathrm{HPO}_{4}$ ions of hydrous layer of OCP unit lattice.

Then, we evaluated the properties of the fabricated OCPsilica, focusing more on the phase-conversion property. When the OCP was immersed in hot water or placed under hydrothermal conditions, it converted to apatite via direct solid-solid phase transformation. ${ }^{\mathbf{1 8 , 1 9 , 2 4}}$ In addition, when the OCP was heated under dry conditions, it converted to tricalcium phosphate (TCP) through the collapse of the OCP structures. Fig. S1† shows the XRD patterns of OCP-silica samples treated in water

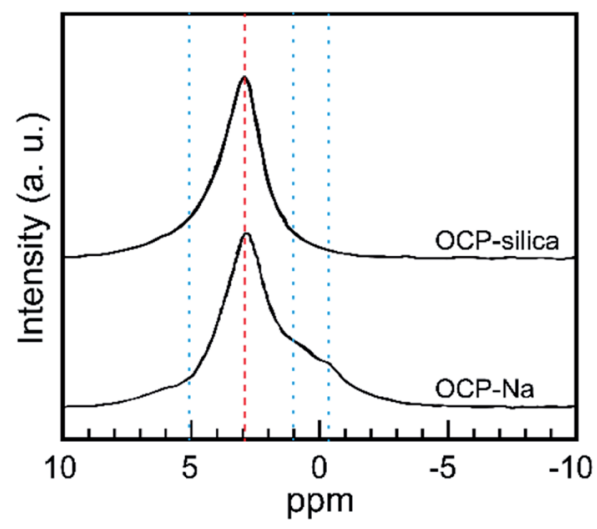

Fig. $7{ }^{31} \mathrm{P}$ solid-state NMR spectra of OCP-silica and OCP-Na. Red broken line: state of apatite layer, blue dotted line: state of hydrous layer. 


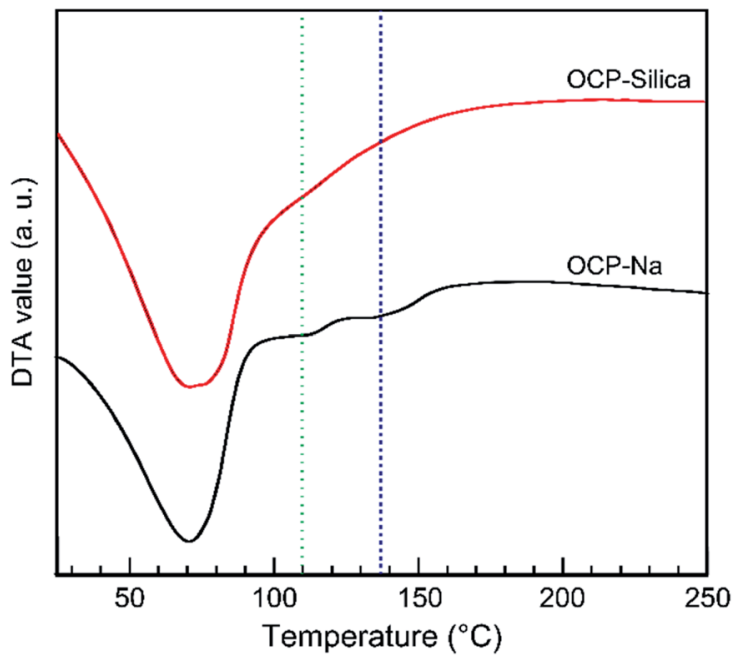

Fig. 8 DTA curve of OCP-silica and OCP-Na. Green and blue broken lines were indicated the collapse of the OCP hydrous layer of OCP. (a) conventional OCP

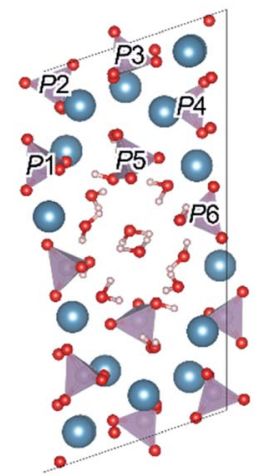

(b) OCP-silica

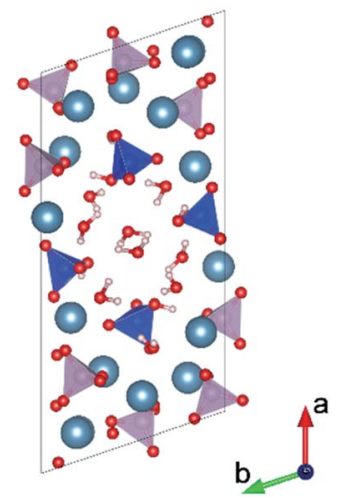

Fig. 9 Schematic illustrations of conventional OCP (a) and OCP-silica (b) crystal structure drawn by VESTA3 programme based on ref. 30 and ${ }^{31}$ Each phosphates were labeled as $P 1$ to $P 6$. Blue tetrahedron indicated $\mathrm{SiO}_{4}{ }^{4-}$
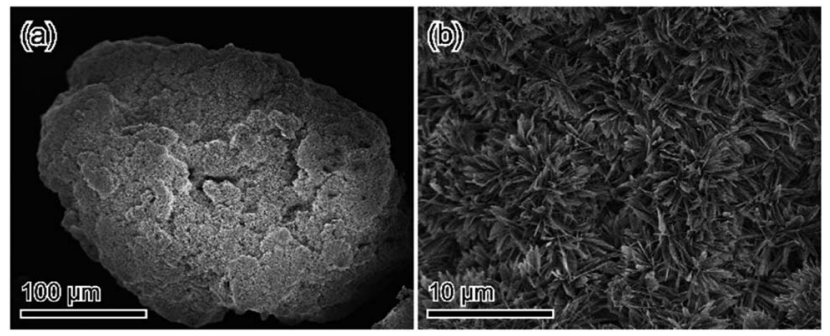

Fig. 10 SEM micrograph of DCPA granules treated in $1 \mathrm{~mol} \mathrm{~L}^{-1}$ $\mathrm{Na}_{2} \mathrm{SiO}_{3}$ : (a) low-magnification image; (b) magnified image.

and in $\left(\mathrm{NH}_{4}\right)_{2} \mathrm{CO}_{3}$ containing solutions. The treated OCP-silica samples transformed into monophasic apatite regardless of the $\left(\mathrm{NH}_{4}\right)_{2} \mathrm{CO}_{3}$ concentration. Moreover, FTIR measurements indicate that the obtained apatite samples contained $\mathrm{CO}_{3}$ as carbonate apatite $\left[\mathrm{CO}_{3} \mathrm{Ap}: \mathrm{Ca}_{10-a}\left(\mathrm{PO}_{4}\right)_{6-b}\left(\mathrm{CO}_{3}\right)_{\mathrm{c}}(\mathrm{OH})_{2-d}\right]$ (Fig. S2 $\dagger$ ). With increasing $\left(\mathrm{NH}_{4}\right)_{2} \mathrm{CO}_{3}$ concentration in the treated solutions, the $\mathrm{CO}_{3}$ content of samples increased, while the silica content slightly decreased. Then, silica-substituted apatite with/without $\mathrm{CO}_{3}$ could be fabricated from OCP-silica via a simple solution-immersion process (Fig. $\mathrm{S} 3 \dagger$ ).

We also evaluated the phase evolution of OCP-silica during dry heat processes. Fig. S4† shows the XRD pattern of samples subjected to dry heat processes. With increasing temperature, OCP-silica converted to monophasic hydroxyapatite (HAp) at $200{ }^{\circ} \mathrm{C}$. Then, with further temperature increase to $600{ }^{\circ} \mathrm{C}$, cristobalite $\left(\mathrm{SiO}_{2}\right)$ peaks were observed with HAp peaks. Above $1000{ }^{\circ} \mathrm{C}$, samples were converted to TCP and cristobalite. Moreover, during heat treatment at above $600{ }^{\circ} \mathrm{C}$, granular particles of 10-30 $\mathrm{nm}$ formed on the OCP-silica surface, which coincides with the XRD results (Fig. $\mathrm{S} 5 \dagger$ ).

The results indicate that during the DCPD hydrolysis process in a solution of suitable $\mathrm{Na}_{2} \mathrm{SiO}_{3}$ concentration, $\mathrm{Ca}, \mathrm{PO}_{4}$, and silica assembled as the OCP structure. The results of STEM-EDX mapping and ${ }^{31} \mathrm{P}$ solid-state NMR showed that silica was intercalated into the OCP hydrous layer, and then a layer-bylayer structure of apatite-silica was formed. In addition, similar to the conventional OCP, OCP-silica could be converted to apatite-containing silica through a simple solutionimmersion process.

Much attention and cost have been channelled toward safely substituting and doping silica to biomaterials. The proposed method is simple and safe, as no organic materials are needed for silica substitution; thus, harmful residual organic matter is avoided.

For biomaterial applications, especially as bone substitutes, at least granule size $(>100 \mu \mathrm{m})$ is needed. ${ }^{25-27}$ The proposed process enables the application of such granules, as calcium hydrogen phosphate anhydrate [DCPA: $\left.\mathrm{CaHPO}_{4}\right]$, the anhydrate phase of DCPD, has excellent formability that allows the formation of granule-shaped materials. ${ }^{16,28,29}$ When DCPA granules (100-250 $\mu \mathrm{m})$ were immersed into $\mathrm{Na}_{2} \mathrm{SiO}_{3}$ solution, OCP-silica granules preserved precursor whole shapes could be obtained (Fig. 10 and S6 $\dagger$ ). Furthermore, when the fabricated OCP-silica granules were immersed into $\left(\mathrm{NH}_{4}\right)_{2} \mathrm{CO}_{3}$ solutions, they converted to HAp, or $\mathrm{CO}_{3} \mathrm{Ap}$ maintained their whole shapes (Fig. S7-S9†). Thus, this method can overcome the bottleneck of safe silica-doping using silica-based materials.

\section{Conclusion}

In conclusion, OCP-silica was fabricated from soluble calcium phosphate through the immersion of DCPD into $\mathrm{Na}_{2} \mathrm{SiO}_{3}$ solution. Silica was intercalated into the OCP hydrous layer, replacing the hydrous structure. When OCP-silica was immersed in aqueous solution, silica-substituted apatite (both HAp and $\mathrm{CO}_{3} \mathrm{Ap}$ ) could be fabricated via one step.

\section{Author contributions}

Y. Sugiura and M. H. did setup of experimental design and performed experiments. K. N. performed TEM and STEM 
observations. Y. Saito and T. E. measured solid-state NMR of samples. Y. Sugiura wrote a manuscript.

\section{Conflicts of interest}

There are no conflicts to declare.

\section{Acknowledgements}

This study is financially supported by KAKENHI for Young Researcher, JP19K19081. We thank Dr Y. Suezawa, K. Yoshihara and T. Nakanishi for helping with FT-IR and XRF measurement. This study is partially supported by the Research centre for Industrial Science \& Technology, Kagawa Industry Support Foundation (RIST Kagawa).

\section{Notes and references}

1 E. M. Carlisle, Science, 1972, 178, 619.

2 S. Wang, X. Wang, F. G. Draenert, O. Albert, H. C. Schröder, V. Mailänder, G. Mitov and W. E. G. Müller, Bone, 2014, 67, 292.

3 I. D. Xynos, A. J. Edgar, L. D. K. Buttery, L. L. Hench and J. M. Polak, Biochem. Biophys. Res. Commun., 2000, 276, 461.

4 D. M. Reffitt, N. Ogston, R. Jugdaohsingh, H. F. J. Cheung, B. A. J. Evans, R. P. H. Thompson, J. J. Powell and G. N. Hampson, Bone, 2003, 32, 127.

5 A. Moorthi, P. R. Parihar, S. Saravanan, M. Vairamani and N. Selvamurugan, Mater. Sci. Eng., C, 2014, 43, 458.

6 Z. Mladenovic, A. Johansson, B. Willman, K. Shahabi, E. Björn and M. Ransjö, Acta Biomater., 2014, 10, 406.

7 J. Nakamura and T. Kasuga, J. Mater. Chem. B, 2014, 2, 1250. 8 G. Dong, Y. Zheng, L. He, G. Wu and C. Deng, Ceramurgia Int., 2016, 42, 883 .

9 A. Manchon, M. Alkhraisat, C. Rueda-Rodriguez, J. Torres, J. C. Prados-Frutos, A. Ewald, U. Gbureck, J. C. Azama, A. Rodriguez-Gonzalez and E. Lopez-Cabarcos, J. Biomed. Mater. Res., Part A, 2015, 103, 479.

10 C. Q. Ning, Y. Greish and A. El-Ghannam, J. Mater. Sci.: Mater. Med., 2004, 15, 1227.
11 A. Obata, S. Tokuda and T. Kasuga, Acta Biomater., 2009, 5, 57.

12 T. Kasuga, H. Maeda, K. Kato, M. Nogami, K. Hata and M. Ueda, Biomater, 2003, 24, 3247.

13 S. Kamakura, Y. Sasano, T. Shimizu, K. Hatori, O. Suzuki, M. Kagayama and K. Motegi, J. Biomed. Mater. Res., 2002, 59, 29.

14 T. Kurobane, Y. Shiwaku, T. Anada, R. Hamai, K. Tsuchiya, K. Baba, M. Iikubo, T. Takahashi and O. Suzuki, Acta Biomater., 2019, 88, 514.

15 Y. Sugiura, M. L. Munar and K. Ishikawa, Mater. Lett., 2018, 212, 28.

16 Y. Sugiura, M. L. Munar and K. Ishikawa,J. Mater. Sci.: Mater. Med., 2018, 29, 151.

17 N. S. Chickerur, M. S. Tung and W. E. Brown, Calcif. Tissue Int., 1980, 32, 55.

18 Y.-H. Tseng, C.-Y. Mou and J. C. C. Chan, J. Am. Chem. Soc., 2006, 128, 6909.

19 Y. Sugiura and K. Ishikawa, J. Solid State Chem., 2018, 267, 85.

20 R. Soda, Bull. Chem. Soc. Jpn., 1961, 34, 1491.

21 W. J. E. M. Habraken, J. Tao, L. J. Brylka, H. Friedrich, L. Bertinetti, A. S. Schenk, A. Verch, V. Dmitrovic, P. H. H. Bomans, P. M. Frederik, J. Laven, P. van der Schoot, B. Aichmayer, G. de With, J. J. DeYoreo and N. A. J. M. Sommerdijk, Nat. Commun., 2013, 4, 1507. 22 Y. Sugiura and K. Ishikawa, Crystals, 2018, 8, 222.

23 Y. Sugiura and Y. Makita, Cryst. Growth Des., 2018, 18, 6165. 24 M. Kamitakahara, N. Ito, S. Murakami, N. Watanabe and

K. Ioku, J. Ceram. Soc. Jpn., 2009, 117, 385.

25 K. Ishikawa, Materials, 2000, 3, 1138.

26 K. Ishikawa, J. Ceram. Soc. Jpn., 2019, 127, 595.

27 A. C. Tas, J. Am. Ceram. Soc., 2011, 94, 3722.

28 K. Tsuru, A. Yoshimoto, M. Kanazawa, Y. Sugiura, Y. Nakashima and K. Ishikawa, Materials, 2017, 10, 374.

29 Y. Sugiura and K. Ishikawa, Mater. Lett., 2019, 239, 143.

30 K. Momma and F. Izumi, J. Appl. Crystallogr., 2011, 44, 1272.

31 M. Mathew, W. E. Brown, L. W. Schroeder and B. Dickens, J.

Crystallogr. Spectrosc. Res., 1988, 18, 235. 